\title{
TUTORIA PRESENCIAL: O DESAFIO DE ALIAR TEORIA E PRÁTICA NO ENSINO HÍBRIDO DE CURSO TÉCNICO PARA O MEIO RURAL
}

\author{
JOÃO PESSOA/PB JULHO/2018 \\ Poliana Souza de Queiroz Lopes - SENAR/PB - poliana@senarpb.com.br \\ Tipo: Relato de Experiência Inovadora (EI) \\ Categoria: Métodos e Tecnologias \\ Setor Educacional: EDUCAÇÃO MÉDIA E TECNOLÓGICA
}

\begin{abstract}
RESUMO
O presente artigo propõe uma reflexão sobre educação a distância e ensino híbrido e apresenta $o$ relato de experiência sobre a tutoria presencial e o processo de capacitação para atuação nas atividades presenciais do Curso Técnico em Agronegócio, ofertado pelo Serviço Nacional de Aprendizagem Rural - Administração Regional da Paraíba, nos Polos de Alagoa Grande, Campina Grande e João Pessoa. Por se tratar de educação técnica de nível médio, com o propósito de formação profissional para o mercado de trabalho, o curso possui metodologia que objetiva conciliar o ensino a distância e o presencial, atender o público residente no meio rural, com atividades teóricas, práticas, mídias on-line e off-line. A partir das capacitações com os agentes presenciais, os alunos passaram a ter um maior engajamento no curso e um melhor desempenho, tanto nas atividades a distância quanto nas atividades presenciais. A hipótese que acreditamos é que no ensino híbrido, um bom desenvolvimento do ensino presencial fortalece o ensino a distância.
\end{abstract}

Palavras-chave: Educação a Distância; Ensino Híbrido; Tutoria Presencial. 


\section{INTRODUÇÃo}

A sociedade contemporânea está, cada vez mais, inserida no mundo digital. A revolução da Tecnologia da Informação e da Comunicação, que já é a grande responsável pelas mudanças na economia global, nas formas de comunicação e relacionamentos entre os sujeitos, redimensionou também a forma de pensar e aprender.

Por outro lado, sabe-se que as instituições educacionais foram construídas, em sua maioria, para a época industrial e não a digital. Por saber que essa revolução tecnológica é irreversível e não apresenta nenhum sinal de enfraquecimento, a educação, assim como a sociedade, vem acompanhando essas transformações.

Para Castells (2005), essa irreversibilidade, determinada pelas TIC's, possibilitam, ao mesmo tempo, a utilização de diferentes formas de linguagem e a organização de novos espaços de aprendizagem, por elas mediados.

Desse modo, a educação configurada como eixo mediador entre o indivíduo e a sociedade, ganha uma nova conjuntura no que diz respeito ao ensino e ao trabalho, no qual a complexidade e o trabalho em rede são as principais características que movem o processo formativo. Dentro desse contexto da complexidade e trabalho em rede, emerge a Educação a Distância (modalidade de ensino mediada pelas tecnologias de informação e de comunicação).

As maiores diferenças entre o ensino a distância e o presencial são os processos de gestão e a mediação pedagógica, no qual a organização e o método do conhecimento ocorrem em tempos e espaços diferentes. A EaD, possui, entre outras vantagens, a flexibilidade de tempo e local, respeitando as individualidades e atendendo as necessidades de seus alunos. Além disso, oportuniza o acesso a democratização do conhecimento.

Acreditando na modalidade do ensino a distância como possibilidade de atender públicos que muitas vezes estão distantes dos centros de ensino, em 2014, o Serviço Nacional de Aprendizagem Rural (Senar)[1] aderiu à Rede e-Tec Brasil, avançou na sua missão e expandiu suas ações com a oferta do ensino técnico de nível médio a distância. A proposta do curso é formar profissionais habilitados nos procedimentos de gestão e comercialização do agronegócio nos diversos segmentos e cadeias produtivas da agropecuária, preparados para atuar no mercado que mais cresce e se transforma no País. 
O Senar-Paraíba foi um dos sete primeiros estados a implantar, em 2015, o curso

Técnico em Agronegócio que possui dois anos de duração e ensino semipresencial, no qual o aluno cursa $80 \%$ das suas atividades a distância e $20 \%$ presencial. A metodologia foi escolhida com o objetivo de conciliar ensino a distância e o presencial, atender 0 público residente no meio rural, com atividades teóricas, práticas, mídias on-line e offline.

Nesse artigo, o objetivo é relatar as experiências com a tutoria presencial e o processo de capacitação de tutores para atuação nas atividades presenciais do Técnico em Agronegócio na regional do Senar-Paraíba. Com a atuação dos tutores presenciais os alunos têm um maior engajamento no curso e um melhor desempenho, tanto nas atividades a distância quanto nas atividades presenciais. A hipótese que acreditamos é que no ensino híbrido, um bom desenvolvimento do ensino presencial fortalece o ensino a distância.

Para o relato dessas experiências com a tutoria presencial e, consequentemente, o fortalecimento do ensino a distância do Curso Técnico em Agronegócio, recorremos a documentação institucional, bem como referências na literatura sobre educação a distância, ensino híbrido, tutoria a distância e presencial e formação de tutores.

\section{REFERENCIAL TEÓRICO}

A Educação a Distância nas últimas décadas se expandiu, principalmente, a partir do desenvolvimento das novas tecnologias. Desde o seu surgimento até os dias atuais, diferentes tecnologias foram incorporadas a esse modelo de ensino. Numa escala cronológica, no início tinham-se livros e guias, em seguida rádio e televisão, depois áudios e vídeos, até chegar a expansão da rede de satélites e a internet. Hoje, os cursos EaD lançam mão de todos esses recursos para melhor desenvolvimento das duas atividades.

Apesar disso, existem muitos conceitos que definem a educação a distância. A distância geográfica, temporal e a necessidade de tecnologia na mediação do processo educativo a distância são as características mais pontuadas pelos autores. Para Gomes (2009) a EaD representa a:

Modalidade educacional, na qual a mediação didático-pedagógica no processo de ensino e aprendizagem ocorre com a utilização de meios e tecnologia de informação e comunicação, com estudantes e professores desenvolvendo atividades educativas em lugares e tempos diversos. (GOMES, 2009, p.22)

De acordo com Moore e Kearsley (2011) a EaD é considerada como: 
(...) o aprendizado planejado que ocorre normalmente em um local diferente do local do ensino, exigindo técnicas especiais de criação do curso e de instrução, comunicação por meio de várias tecnologias e disposições organizacionais e administrativas especiais. (MOORE e KEARSLEY, 2011 p.2)

A partir da contribuição dos autores é possível dizer que a EaD consiste, principalmente, na forma de educação em que aprendizado é realizado a distância e o processo de ensino-aprendizagem é mediado por tecnologias, onde professores e alunos não estão no mesmo espaço físico e temporal. Apesar de estarem separados espacial e temporalmente, eles estão conectados por meio de ferramenta da tecnologia responsável por permitir a comunicação e a interação entre os integrantes.

Os autores Brutscher, Sampaio e Pereira (2007) concordam entre si e consideram que a EaD, apoiada fortemente nas TIC's, democratiza o acesso à educação, pois:

\begin{abstract}
Ela alcança pessoas num espaço territorial maior, com menor custo; ampliando o acesso, inclusive, a quem mora longe de centros universitários. Além disso, ao flexibilizar horários, ela permite ao estudante maior liberdade e autonomia na construção do conhecimento, atendendo às demandas de formação de pessoas que por estarem envolvidas em processos de trabalho tem maiores dificuldades em compatibilizar os seus horários com os das formações presenciais. Devido aos recursos disponíveis, a Educação à Distância se aprimorou e ampliou suas vantagens de liberdade para estudo e maior horizontalidade no processo de aprendizagem. (BRUTSCHER; SAMPAIO; PEREIRA, 2012, p. 477)
\end{abstract}

Para considerar as mais diferentes realidades de acesso à educação e a democratização do conhecimento, existem vários modelos de EaD que utilizam diferentes tecnologias.

Atualmente, os recursos tecnológicos mais usados na mediação em EaD são: a televisão, o rádio, o material impresso e os computadores, sobretudo a internet. Independente da mais adequada e da mais utilizada em cada processo, é indiscutível o papel essencial que a tecnologia representa para a educação a distância.

Por outro lado, quando se fala em ensino híbrido, deve-se levar em consideração a combinação do processo de ensino presencial com o a distância, o uso de tecnologias e de modalidades, e as diversas mídias. Nesse contexto, o híbrido é entendido como:

[...] misturado, mesclado, blended. A educação sempre foi misturada, híbrida, sempre combinou vários espaços, tempos atividades, metodologias, públicos. Esse processo, agora, com a mobilidade e a conectividade, é muito mais perceptível, amplo e profundo: é um ecossistema mais aberto e criativo. Podemos ensinar e aprender de inúmeras formas, em todos os momentos, em múltiplos espaços. Híbrido é um conceito rico, apropriado e complicado. (Moran, J. 2015, p. 22)

Desse modo, ao ofertar um curso que possui essa modalidade é preciso considerar as duas formas de ensino e utilizar atividades que trabalhem a parte a distância e a parte 
presencial e reforcem tanto a teoria como a prática. Dentro desse contexto, surgem os novos agentes no processo ensino-aprendizagem: os tutores. O termo Tutor, do latim Tutore, tem como significado encarregado de tutelas, cuidar, proteger alguém.

Para Bruno e Lemgruber (2009, p.7), conforme citado por Mattar (2012, p.xxiv) "Este profissional, como mediador pedagógico do processo de ensino e aprendizagem, é aquele que também assume a docência e, portanto, deve ter plenas condições de mediar conteúdos e intervir para a aprendizagem". Por isso, na prática, esses agentes possuem um papel de grande responsabilidade na EaD, pois é de fundamental importância que eles tenham conhecimentos específicos técnicos e competências para trabalhar estratégias de mediação nos cursos, tanto na parte a distância quanto na parte presencial.

\section{TUTORIA PRESENCIAL: RELATO DE EXPERIÊNCIA NO SENAR-PB}

O curso Técnico em Agronegócio de 1.230 horas, é totalmente gratuito, ofertado na modalidade semipresencial, com $80 \%$ do curso a distância e $20 \%$ da carga horária presencial em polos de apoio presencial e em visitas técnicas.

Os polos de apoio presencial têm a importante função de apoio pedagógico e administrativo para os alunos do ensino a distância, uma vez que nos encontros presenciais são realizadas atividades práticas e são espaços para discussão e interação entre os agentes do processo de ensino.

Na regional do Senar-PB existem hoje três Polos de apoio presencial localizados nos municípios de Alagoa Grande, e de Campina Grande (operacionalizados com a parceria dos sindicatos rurais) e de João Pessoa (que funciona na sede do Senar-PB). Já foram formadas 7 turmas, 177 técnicos, estamos com 12 turmas em andamento e 346 alunos.

Conforme o projeto pedagógico, embora a maior parte da carga horária do curso seja realizada a distância, por meio das diferentes tecnologias de informação e comunicação, por se tratar de educação técnica de nível médio, com o propósito de formação profissional para o mercado de trabalho, o curso Técnico em Agronegócio prevê $20 \%$ de carga horária presencial, não apenas para avaliações presenciais, mas para o exercício de atividades práticas profissionalizantes, nos polos de apoio presencial e/ou em locais demonstrativos de produção (empresas e propriedade rurais) com o acompanhamento do tutor presencial.

De forma detalhada, na formação técnica do Senar, o tutor a distância é responsável por 
acompanhar todo o processo de ensino-aprendizagem no Ambiente Virtual de Aprendizagem (AVA), sendo o mediador dos fóruns e dos chats, bem como responsável pelas avaliações a distância. Já o tutor presencial é responsável pela realização de aulas com os principais conteúdos das unidades curriculares, de atividades que demonstram na prática toda a teoria que está sendo estudada, de visitas técnicas à propriedades e empresas rurais com o intuito de aproximação da formação com o mercado de trabalho e de elaboração e aplicação de avaliações presenciais. São utilizadas metodologias ativas no processo de ensino-aprendizagem a partir de práticas, por exemplo, como a sala de aula invertida, no qual o aluno estuda a teoria a distância e a aplicação da prática em sala de aula presencial.

Nesse sentido, o papel do tutor não é restrito ao de monitor, motivador ou repassador de avisos. Atualmente, o Senar-PB conta com mais de 40 tutores credenciados e atuantes que possuem desempenho como o de um professor e um grande desafio: aliar teoria e prática.

\subsection{Capacitação de tutores presenciais}

Diante desse cenário de mudanças e avanços significativos no ensino híbrido, com a emergência de novos espaços - os polos e novos agentes - os tutores, cuja função vem adquirindo novas habilidades e conquistando lugar no processo de educação, entendemos enquanto regional que se faz necessário investir na formação específica desses agentes.

Sobre a construção do conhecimento e a própria formação e capacitação, Libâneo (2007) pontua:

\footnotetext{
A formação continuada pode possibilitar a reflexividade e a mudança nas práticas docentes, ajudando os professores a tomarem consciência das suas dificuldades, compreendendo-as e elaborando formas de enfrentálas. De fato, não basta saber sobre as dificuldades da profissão, é preciso refletir sobre elas e buscar soluções, de preferência, mediante ações coletivas (LIBÂNEO, 2007, p.20).
}

Para garantir a profissionalização e melhor atuação dos tutores presenciais do curso, seja no domínio de recursos tecnológicos ou na reflexão da sua prática técnica, passamos a realizar capacitações para que esses agentes tenham possibilidade de conhecer e compartilhar experiências em tutoria, bem como construir ações em conjunto que colaborem com a formação dos alunos.

Semestralmente[2], no início de cada período, são organizados encontros com programação de informações e formação docente para os tutores presenciais de todas 
as unidades curriculares do Técnico em Agronegócio, atuantes nos três polos da Paraíba: Alagoa Grande, Campina Grande e João Pessoa. São compartilhadas as especificidades do curso e o aperfeiçoamento da formação dos tutores, por meio de palestras, dinâmicas em grupos, explanações orais, vídeos e oficinas que abordam temas como: aspectos didáticos para ministrar boas aulas, o perfil do aluno e do tutor do curso semipresencial, a importância de se considerar as demandas e necessidades do aluno - o protagonista do processo ensino-aprendizagem, a conceituação e diferença entre planejamento e plano de aula, as propostas de avaliações formativas, a construção de atividades presenciais que destaquem as vivências práticas e a contextualização de atividades relacionadas ao setor agropecuário regional, as metodologias ativas aplicadas ao curso, atualização tecnológica e procedimentos administrativos.

Dentre os assuntos abordados nos encontros presenciais, a abordagem sobre metodologias ativas ganha destaque, pois é considerada um divisor de águas na execução do curso. As metodologias ativas são caracterizadas como processos mais criativos para o ensino e a aprendizagem, no qual se propõe a construção do conhecimento a partir de fontes múltiplas, tendo o aluno como seu protagonista e o professor no papel de orientador e facilitador do processo de aprendizagem. Foram trabalhadas nas capacitações e passaram a ser utilizadas pelos tutores presenciais do curso, metodologias como: sala de aula invertida, discussão de temas, trabalhos em equipe, estudos de casos, debates, brainstorming, simulações, elaborações de questões, dinâmicas e ferramentas para interatividade.

Além dos encontros semestrais, realizamos o planejamento pedagógico das unidades curriculares. A intenção é fazer com que os tutores de cada polo de apoio possam compartilhar as experiências técnicas e didáticas nas unidades que vão atuar, abordando os mesmos pontos nos encontros presenciais. Assim, os alunos dos três polos vão receber a mesma capacitação.

O planejamento acontece presencialmente ou por meio da ferramenta de comunicação instantânea - Skype que, como lembra Mattar (2012), de forma gratuita é utilizada pelos professores como plataforma para EaD.

A partir da formação continuada (por meio de encontros e planejamentos das aulas) de tutores presenciais, tivemos mudanças de paradigmas em sala de aula e a inversão do modelo tradicional de ensino.

Esses resultados são aferidos, hoje, por meio de formulários eletrônicos do Google 
Forms, ferramenta do Google que permite a coleta e análise de dados e facilita o processo de avaliação, neste caso da aprendizagem, do material didático e do desempenho dos tutores presenciais e a distância do Técnico em Agronegócio. Os resultados apontam que os encontros presenciais são o grande diferencial do curso, pelo acesso a vivência prática com atividades em sala de aula e visitas técnicas. Esse diferencial é apontado também com relação aos demais cursos a distância que os alunos já tiveram a oportunidade de participar e, inclusive, ao ensino nas próprias universidades que ainda possuem modelo tradicional e se detêm prioritariamente a teoria.

Registramos também que, após o início das capacitações e melhor acompanhamento das atividades presenciais, tivemos uma diminuição na evasão nas turmas e um melhor rendimentos dos alunos no curso.

O desafio permanente é continuar capacitando os tutores para que, além dos aspectos técnicos, eles tenham práticas e métodos que aproximem do ensino que está sendo realizado a distância e que tornem as aulas mais didáticas, de melhor compreensão e mais associadas com a realidade do meio rural e do mercado de trabalho.

\section{CONSIDERAÇÕES FINAIS}

Diante do contexto do ensino a distância, a função do tutor como mediador do processo de aprendizagem é de fundamental importância para que o aluno tenha uma maior aproximação com a modalidade e um bom desempenho durante o curso.

Neste sentido, o Técnico em Agronegócio, ofertado pelo Senar, por ser semipresencial e ter metodologia de ensino híbrido, favorece a realização de atividades educacionais que conciliam a construção dos conhecimentos teóricos com os conhecimentos práticos, por meio de vivências em sala de aula que resgatam a aplicação da teoria e aproximação da atividade profissional

A partir dos encontros de formação dos tutores presencias e planejamento das unidades curriculares dos três polos de apoio presencial administrados pelo Senar-PB, percebemos que esses momentos propiciam o compartilhamento de experiências dos semestres passados e possibilitam a discursão do planejamento das atividades a serem desenvolvidas no semestre em curso, estimulando práticas criativas e melhoram 0 processo de ensino-aprendizagem.

Por outro lado, os alunos reconhecem as melhorias apresentadas e nas respostas dos 
formulários enaltecem o trabalho desempenhado pelos tutores presenciais. Por estar mais próximo do aluno, o tutor presencial é ainda responsável por estimular a relação do aluno com o tutor a distância. Dessa forma, acreditamos que ao capacitar o tutor presencial, estamos diretamente fortalecendo a função do tutor a distância. Os resultados são comprovados com o maior engajamento e desempenho dos alunos e a continuidade no curso.

\section{Referências}

BLANCO, E.; SILVA, B. D. Tecnologia Educativa em Portugal: conceito, origens, evolução, áreas de intervenção e investigação. Revista Portuguesa de Educação, Portugal, 1993.

BRUTSCHER, Volmir José; et al. Potencialidades da educação a distância: modalidades em consolidação. Revista Brasileira de Ciências da Saúde, João Pessoa, v. 16, n. 3, p. 475-480, 2012. Disponível em: Acesso em: 22 mar. 2018.

CASTELLS, Manuel. A Sociedade em Rede. São Paulo: Paz e Terra, 2005.

LITTO, Frederic M. FORMIGA, Marcos M. (Org.). Educação a distância: o estado da arte. São Paulo: Pearson Education do Brasil, 2009.

GOMES, C.A. da Costa. A história da EAD no mundo. In: Educação a distância. O estado da arte. ABED. p.2-08. São Paulo: Pearson Education do Brasil. 2009.

MATTAR, João. Tutoria e interação em educação a distância. São Paulo: Cengage Learning, 2012.

MOORE, Michael G. e KEARSLEY, Grey. Educação a distância: uma visão integrada. [traduação Roberto Galman]. São Paulo: Cengage Learning, 2011.

MORAN, J. in: BACHIC, Lilian; TANZI NETO, Adolfo; TREVISANI, Fernando de Mello (org). Ensino Hibrido: personalização e Tecnologia na Educação. Porto Alegre: Penso. 2015.

[1] O Senar tem como missão realizar a Educação Profissional, a Assistência Técnica e as atividades de Promoção Social, contribuindo para um cenário de crescente 
desenvolvimento da produção sustentável, da competitividade e de avanços sociais no campo.

[2] Já foram realizados cinco encontros de capacitação de tutores, em dois anos. 